\title{
On the globalization of stock markets: An application of Vector Error Correction Model, Mutual Information and Singular Spectrum Analysis to the G7 countries
}

\author{
Rui Menezes ${ }^{\mathrm{a}}$, Andreia Dionísio ${ }^{\mathrm{b}, *}$, Hossein Hassani $^{\mathrm{c}}$ \\ a ISCTE Business School, Av das Forças Armadas, 1649-026 Lisboa, Portugal \\ b University of Évora and CEFAGE-UE, Largo dos Colegiais, 2, 7000-803 Évora, Portugal \\ ' Cardiff School of Mathematics, Cardiff University, Cardiff CF24 4AG, United Kingdom
}

\section{A R T I C L E I N F O}

\section{Article history:}

Received 14 October 2010

Received in revised form

20 September 2012

Accepted 2 October 2012

Available online 13 October 2012

\section{JEL classification}

C14

$\mathrm{C} 22$

F02

\section{Keywords:}

Globalization

Market integration

Vector Error Correction

Mutual Information

Singular Spectrum Analysis

\begin{abstract}
A B S T R A C T
This paper analyzes stock market relationships among the G7 countries between 1973 and 2009 using three different approaches: (i) a linear approach based on cointegration, Vector Error Correction (VECM) and Granger Causality; (ii) a nonlinear approach based on Mutual Information and the Global Correlation Coefficient; and (iii) a nonlinear approach based on Singular Spectrum Analysis (SSA). While the cointegration tests are based on regression models and capture linearities in the data, Mutual Information and Singular Spectrum Analysis capture nonlinear relationships in a non-parametric way. The framework of this paper is based on the notion of market integration and uses stock market correlations and linkages both in price levels and returns. The main results show that significant co-movements occur among most of the G7 countries over the period analyzed and that Mutual Information and the Global Correlation Coefficient actually seem to provide more information about the market relationships than the Vector Error Correction Model and Granger Causality. However, unlike the latter, the direction of causality is difficult to distinguish in Mutual Information and the Global Correlation Coefficient. In this respect, the nonlinear Singular Spectrum Analysis technique displays several advantages, since it enabled us to capture nonlinear causality in both directions, while Granger Causality only captures causality in a linear way. The results also show that stock markets are closely linked both in terms of price levels and returns (as well as lagged returns) over the 36 years analyzed.
\end{abstract}

(c) 2012 The Board of Trustees of the University of Illinois. Published by Elsevier B.V. All rights reserved.

\section{Introduction and literature review}

Many empirical studies on stock market globalization rely on linear models of returns. Other studies adopt a closed-form nonlinear approach to capture specific types of data nonlinearities (e.g., GARCH-type models, regime switching, etc.). Previous studies that address the issue of financial market globalization include, for example, Ammer and Mei (1996), Arshanapalli and Doukas (1994), Bekaert and Harvey (1995), Chung and Liu (1994), Drożdż, Grümmer, Ruf, and Speth (2001), Hamao, Masulis, and Ng (1990), Kasa (1992), Masih and Masih (1997, 2002), Tavares (2009) and Zhou and Sornette (2003). Some of these studies, however, may suffer from two main drawbacks. First, financial market linkages appear to be more complex than what can be captured by linear models. These linear models may be unsuitable to deal with distribution shifts that often occur over time such as structural breaks,

\footnotetext{
* Corresponding author.

E-mail addresses: rui.menezes@iscte.pt (R. Menezes), andreia@uevora.pt
} (A. Dionísio), hassanih@cf.ac.uk (H. Hassani). regime shifts and other kinds of nonlinearities, especially when the data series are relatively long. In addition, distribution-free nonlinearities are difficult to accommodate within linear models that rely on restrictive distribution assumptions. Secondly, return data are typically computed as the first log price difference and the long-run information contained in the original price data is thus removed. What is recorded is the price data that contains both longrun trends and short-run adjustment information and any existing long-run stochastic trend is removed by differencing. Thus, using prices along with returns may provide a better framework for the analysis of market globalization.

In seeking to address these problems, this study presents some results on stock market globalization among the G7 countries using price and return data on the basis of three different approaches: (i) a linear approach based on cointegration, Vector Error Correction and Granger Causality; (ii) a nonlinear approach based on Mutual Information and the Global Correlation Coefficient; and (iii) a nonlinear approach based on Singular Spectrum Analysis. While the cointegration and Granger Causality tests are based on regression models and have been used to capture linearities in the data, Mutual Information and Singular Spectrum Analysis are well suited 